УАK 327

ББК 66.4(0)

DOI 10.22394/1682-2358-2017-6-37-45

S.Yu. Zaytsev, post-graduate student of the Faculty of Political Science, Saint-Petersburg State University

\section{INTERACTION OF TRANSNATIONAL CORPORATIONS AND THE STATE: POLITICAL ANALYSIS}

The author considers the activities of transnational corporations as participants in the political process. It is proved that, using different strategies of behavior when interacting with the state, TNCs are able to achieve their economic and political goals.

Key words and word-combinations: transnational corporations, the state, globalization, risks.
С.Ю. ЗайцеВ, аспирант факультета политологии Санкт-Петербургского государственного yниверситета (email:s.zaycev@epsis.ru)

\section{ВЗАИМОАЕЙСТВИЕ ТРАНСНАЦИОНААЬНЫХ КОРПОРАЦИЙ И ГОСУААРСТВА: ПОАИТОАОГИЧЕСКИЙ \\ АНААИЗ}

Аннотация. Рассматривается деятельность транснациональных корпораций как участников политического процесса. Доказывается, что, используя различные стратегии поведения при взаимодействии с государством, ТНК способны добиваться своих экономических и политических целей.

Ключевые слова и словосочетания: транснациональные корпорации, государство, глобализация, риски.

$\mathrm{P}$ числа участников мировых политических и экономических процессов привели к тому, что важную ромь в мировом развитии стами играть такие акторы, как транснациональные корпорации (ТНК). Благодаря развитию производственных технологий, транспортной инфраструктуры, а также изменениям в политико-экономической сфере (Аемократизация политических систем, миберамизация экономики и свобода перемещения капиталов), ТНК смогми конвертировать свой экономический капитац в политические Аействия и вмияние на госу- 
Аарство. Именно поэтому транснациональные корпорации стали объектом интереса всего спектра общественных дисџиплин.

Основной вкцаА в изучение деятельности ТНК внесли преАставители экономической науки, уделив внимание таким аспектам, как потоки прямых иностранных инвестиций [1], конкуренщия с Аругими бизнес-единиџами [2], рост фирмы за счет снижения трансакщионных издержек [3]. Специалисты по международным отношениям рассматривают место транснациональных корпораций в современном мироустройстве и глобальном порядке [4] . ПреАставители управленческих наук анацизируют взаимоотношения между штабквартирой и дочерними компаниями ТНК [5], а также меры повышения эффективности деятельности фирм [6]. Соблюдение прав человека, трансграничное взаимодействие и соџиальная ответственность ТНК являются объектами изучения юридических дисџиплин [7]. При анализе взаимодействия ТНК и современных государственных институтов целесообразно использовать инструментарий политической науки.

Политологи могут рассматривать ТНК как участников политических процессов, способных перевести свой экономический капитал во властные ресурсы. Это позволяет им влиять на принятие решений государства как основного политического субъекта, обладающего цегитимностью, а также законодательными, управленческими и прочими инструментами, тем или иным образом формирующими соџиальную среду.

Проанализировав подходы различных научных дисциплин, транснациональные корпорации можно определить как крупные бизнес-компании, имеющие единую глобальную стратегию развития и стремящиеся к доминирующему положению на рынках нескольких стран путем развития сети филиалов и дочерних фирм и относительно неограниченного инвестирования капитала.

Ключевым показателем развития ТНК явмяется работа их зарубежжных фимиалов и дочерних фирм. Это подтверждается как высоким интересом к этому аспекту со стороны научного сообщества [8], так и статистическими Аанными межАународных организаций. По данным ЮНКТАА, в 2012 г. объем продаж зарубежных филиалов ТНК составил порядка 26 трлн долмаров, что на 7,4\% больше, чем годом ранее. Работает в этих компаниях 72 млн человек [9, с. 8] . Наличие разветвленной сети филиалов делает Аля ТНК необходимым взаимодействие с государственными институтами разных стран дмя успешного развития своей бизнес-деятельности. Приоритет экономических интересов перед остальными отмечает и О.Н. Холдоров, анализируя ТНК как важных акторов мировой политики [10] .

ОАин из ведущих исследователей транснаџиональных (многонаџиональных) корпораций Р. Вернон рассматривал их деятельность и взаимоотношения с правительствами развитых и развивающихся стран [11]. Аля удобства представления основных точек противоречий межку ними приведем результаты анализа Р. Вернона в табличный виА (табл. 1). 
Таблища 1

Точки противоречий межАу ТНК и правительствами разАичных стран

Противоречия между ТНК
и правительствами развитых стран
Сфера национальной безопасности.
Филиалы корпораций, работающих на
территории вражеской страны или ее
сателлитов, исправно выполняли взятые на
себя обязательства по созданию и поставке
товаров и технологий для военных нужд
Коллективные действия ТНК и пра-
вительств через создание европейских
консорциумов в высокотехнологических
отраслях.
Такие объединения сопровождались
проблемами координации между группами
работников из разных стран. В случае
политического кризиса или избрания
нового правительсва в одной из стран-
участниц консорциума, корпорации несли
временные и финансовые издержки из-за
изменений условий работы

Противоречия между ТНК и национальными профсоюзными объединениями.

Лидеры последних считают деятельность ТНК угрозой становлению государству всеобщего благоденствия

Риск утраты рабочих мест, накопленных сбережений граждан и запасов иностранной валюты внутри страны

Использование транснациональными корпорациями «налоговых гаваней», приводящее к недополучению денежных поступлений в бюджет страны-хозяйки. Сюда же можно отнести различия в налогообложении в принимающих странах и странах базирования, когда налоговые ставки способствуют более выгодному ведению бизнеса за рубежом
Идеологические противоречия между правительством и ТНК.

Иностранные инвесторы и бизнесмены предпочитают действовать в стабильной и доброжелательной экономической среде. Поэтому в случае прихода к власти «правых» правительств ТНК расширяли свою деятельность в стране, а при укреплении «левых» сил старались снизить риски и сократить уровень участия в экономике такой страны

Ассоциирование мощи ТНК с мощью стран, в которых находятся штаб-квартиры этих компаний

Историческое наследие, выражающееся в деятельности ТНК, ставшей результатом неравноправных позиций сторон или несправедливых отношений, существовавших в прошлом

Требования правительств принимающих стран привлекать местных бизнесменов в качестве партнеров дочерних компаний крупных корпораций

Так как в проџессе глобализаџии не снимается проблема разделения на развитые и развивающиеся страны, то транснациональные корпорации будут стремиться к извлечению выгоды из такого положения дец. С Аругой стороны, нельзя однозначно утверждать, что их действия будут оказывать негативное влияние на принимающие страны. Ведь во многих случаях именно приход в 
страну крупного бизнеса и выстраивание местным правительством отношений с веАущими ТНК способствовали перехоАу из развивающихся в развитые страны (Южная Корея, Сингапур, отчасти Китай и др.).

Американские исследователи Аж. Бадуэн и Т. Бревер рассматривают взаимоотношения государства и международного бизнеса с позиџий поведенческого подхода. Аля ученых ТНК являются акторами, которые придерживаются определенных форм политического поведения дия достижения своих стратегических целей. Их влияние направлено на участников, расположенных вне рыночной среды - государство, группы интересов, интемлигенџию, общество и осуществляется путем таких действий, как уступки, уклонение от соблюдения законов, переговоры, сотрудничество, формирование коамиџий, кооптация $[12$, с. $120-121]$.

На основе этих предпосылок исследователи выделици две стратегии поведения ТНК при взаимодействии с государством - переговорные (bargaining) и непереговорные (nonbargaining). В центре переговорных стратегий цежкит возможность торга и пересмотра условий деятельности ТНК в стране, изменение форм взаимоотношений между бизнесом и правительством и т.А. Непереговорные стратегии применяются в тех случаях, когда к деятельности ТНК предъявмяются жесткие безусловные требования, которые необходимо неукоснительно соблюдать.

Аля удобства представления приведем используемые стратегии поведения ТНК в табцичный виА, а затем дадим их краткое описание (табл. 2).

Стратегии поведения ТНК при взаимодействии с государством

Таблица 2

\begin{tabular}{c|c}
\hline \multicolumn{1}{c|}{ Переговорные } & \multicolumn{1}{c}{ Непереговорные } \\
\hline Партнерство & Соблюдение \\
Получение выгоды обоими & Удовлетворение существующими \\
участниками взаимодействия & институциональными условиями \\
Ориентация на долгосрочное & Прозрачность правил игры \\
сотрудничество & \\
Конфликт & Избегание \\
Игра с нулевой суммой & Уход корпорации из страны \\
Стремление к полному & Закрытие филиалов \\
присвоению ренты & Снижение инвестиций \\
& Обход \\
& ТнК не удовлетворены существующими \\
& правилами \\
& Использование незаконных методов работы
\end{tabular}

К переговорным политическим стратегиям $\Lambda$. Бадуэн и Т. Бревер относят партнерство и конфликт. В основе такого вида поведения иежат следующие предпосыцки: во-первых, корпорации хотят экспортировать товары, инвестировать за рубежом, вступать в альянсы с Аругими фирмами дия увеличения прибыли и Аоли в мировом рынке, а также Аиверсифиџировать географи- 
ческие риски, чтобы получить Аоступ к ресурсам Аругих стран; во-вторых, правительство имеет свои собственные интересы, выражающиеся в минимизаџии зависимости от Аругих стран и зарубежных фирм, а также стремятся к экономическому росту и конкурентоспособности; в-третьих, правительства не всегда могут навязать свою волю иностранным фирмам, поскольку последние не могут быть принуждены к инвестированию или торговле [12, с. 129].

В обстановке конфликта межАу ТНК и правительством последнее стремится присвоить себе ренту или большую ее часть, полученную от предпринимательской деятельности в стране. В свою очередь, бизнес пытается вернуть или оставить у себя прибыль. Здесь правительство и корпорации выступают участниками игры с нулевой суммой, стремясь к получению еАиноличного выигрыша и установлению контроля над ресурсами. Между ТНК и государством осуществляется торг, в котором каждый из акторов пытается уменьшить выгоды Аругого и получить прибыль за его счет. Такая ситуация возникает при равном или близком к равному объему ресурсов у государства и ТНК.

В основе партнерского поведения межкит получение выгоды обоими участниками взаимодействия - правительства и ТНК. Аля такого типа поведения характерны переходы от краткосрочных сделок к Аолговременным отношениям, от конфликта к кооперации или совместному управлению, от зависимости к взаимозависимости, от поиска возможностей сотрудничества к выстраиванию доверительных отношений [12, с. 130] .

К непереговорным политическим стратегиям А. Бадуэн и Т. Бревер относят стратегии соблюдения (compliance), избегания (avoidance) и обхода (circumvention). В таких случаях государство обладает политическими ресурсами по созданию законных барьеров или стимулов, способствующих эффективному развитию экономики и рынков. Транснациональным корпорациям позволен ввоз капитала и разрешена деятельность по установленным суверенным госуАарством правикам игры.

Многие межаународные и инвестиџионные фирмы удовлетворены существующими требованиями, созданными правительствами домашних или принимающих стран. Транснационацьные корпорации соблюдают установленные правила по рялу причин: а) правительство не сильно ограничивает действия фирмы и ее бизнес-операции; б) правительство обеспечивает привлекательные условия дмя инвестиций (налоговые отсрочки или «каникулы»); в) правительство Не ПодАается КОНтролю и вАиянию со стороны отАеАьной корпораџии [12, с. 128].

В том случае, если сформированные правила не удовлетворяют бизнес, то корпорации используют стратегии избегания, вывозя капитал из страны, сокращая объемы производства и вложений, закрывая зарубежные филиалы и т.п.

Стратегии обхода используются в том случае, если корпорация не удовлетворена правилами, но, по тем или иным причинам, не хочет уходить из страны. Тогда применяются незаконные методы работы (контрабанда, создание местных «подставных» фирм). ОАнако в случае обнаружения фирма может понести большие потери от такого способа ведения бизнеса.

Таким образом, важно понять, какими способами осуществляется взаи- 
модействие межау государством и транснациональными корпорациями: через формулирование и соблюдение «правиц игры» и их институџиональное закрепление или же путем прямого взаимодействия межку государством и ТНК. От правильного выбора стратегии взаимодействия с государством зависит успешность работы фирмы в стране.

Как отмечалось, выбор необходимой стратегии при взаимодействии ТНК и государства обусловлен нацичием и объемом доступных участникам ресурсов. Помимо этого, важной переменной явцяется установценный в принимающей стране политический режим. Именно виА политического режима - демократический или авторитарный - опредемяет те проблемы, с которыми сталкиваются транснациональные корпорации в своей деятельности. Ограничимся анализом тех проблем, с которыми сталкиваются ТНК при взаимодействии с государством с авторитарным политическим режимом.

Важной политической проблемой ТНК в странах с авторитарными режимами явмяется коррупџия, то есть взаимодействие межАу экономическими и политическими акторами, позволяющее за определенные материальные и нематериальные блага добиваться необходимых преференций мия фирмы.

Анализ коррупционных практик производится исходя из Авух посылов. С одной стороны, транснациональные компании способны переносить такие практики из одной страны в Аругую, тем самым участвуя в процессе глоба-

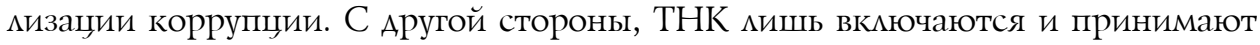
уже существующие виды коррупџионного поведения.

Из участия в коррупции обе стороны могут извлекать выгоды. ОАнако проигравшей стороной оказываются граждане страны, в которой отношения ТНК и государственных институтов строятся на коррупџионном базисе. Так, в 2011 г. нефтяные компании Shell и Eni заплатили 1,1 мирА домларов за месторождение OPL-245 у побережья Нигерии. ОАнако эти Аеньги использовацись не на благо граждан страны, а были преАназначены бывшему министру природных ресурсов $\Lambda$. Этете, который через подставные компании владел этим месторождением. Благодаря раскрытию переписки топ-менеджеров Shell, организация Global Witness в докладе «Shell knews» указывает, что руководство компании знало, что деньги перейдут высшим чиновникам нигерийского правительства [13]. Расследования правоохранительных органов Великобритании, Италии, Гомиандии и США негативно сказались на настроениях инвесторов к Shell, в том числе тех мюдей, которые доверяли ей свои пенсионные накопмения (преимущественно британцы).

Большие риски Аля деятельности ТНК в авторитарных странах несет перспектива экспроприации или национацизации собственности. Пик применения инструмента экспроприации пришелся на середину 1970-х годов, а затем пошел на спаА. ОАнако в начале 2000-х годов, с приходом к власти в Матинской Америке представителей «мевых» сим (прежде всего Уго Чавеса и Эво Моралеса), интерес к Аанной проблеме вновь стал возрастать. Руководство стран, проводящих политику экспроприации, преследует следующие цели:

1) перенос ответственности за неудачную экономическую и соџиальную политику на иностранные компании; 
2) усимение популистской риторики Аля мобилизации массовой поААержки;

3) пополнение государственного бюджета за счет присвоения прибыли;

4) передел собственности с целью удовлетворения аппетитов политической эмиты;

5) устранение конкурентов другими рыночными игроками;

6) стремление стать страной базирования Амя ТНК в рамках процессов авторитарной модернизации.

В целом можно отметить, что в той или иной степени с помощью нащионализаџии авторитарный мидер стремится удержать свое положение, а, обладая возможностью управцять большими ресурсами, он может реализовывать свой политический курс независимо от степени влияния других акторов.

ОАним из наиболее ярких случаев политики национализаџии последнего времени является Венесуэла в периол президентства Уго Чавеса (19992013). 3Аесь национализация в нефтяном и банковском секторах хорошо укмадывалась в рамки идеологии «соџиализма XXI века» (оглашена в июле 2005 во время телеобращения к наџии), в основании которой межало намерение увеличить государственное вмешательство в экономику и изменить систему распределения нефтяных Аоходов.

Популизм как основание политики и риторики Уго Чавеса требовал изменения экономической модели в сфере перераспределения нефтяной ренты. Аля этого были преАприняты такие шаги, как установмение полного контроля наА компанией PDVSA, которая, несмотря на то что явмялась государственной, получила определенную свободу в ходе миберальной политики предыдущего правительства и действовала сообразно своим бизнес-интересам, сАавая в аренду иностранным компаниям богатые ресурсами территории. PDVSA сама не разрабатывала нефтеносные участки, а мишь участвовала в соглашениях о раздеме продукщии с ведущими ТНК в данной отрасли (Exxon Mobil, Total, ConocoPhillips и Ap.).

Ряд шагов, ориентированных на повышение уровня участия государства в нефтяном секторе, коснулся и иностранных ТНК. Это прежде всего касается увеличения налога на неАропользование в 2004 г. (с 1 до 16\%), налога на прибыль дмя иностранных компаний (с 34 до 50\%), а также получение государством контрольного пакета акщий в новых и в уже работающих преАприятиях. Большинство зарубежных ТНК согласились с преАложенными условиями и размером компенсации. Так, доля французской Total в одном из совместных предприятий снизикась с 47 до 30\%. Согласно принятым законам к PDVSA перешии 60\% акщий, а оставшиеся почти 10\% - норвежской Statoil. В ходе переговоров была определена также компенсация в размере 1,8 млрА Аомларов Аля этих компаний. ОАнако два нефтяных гиганта - ExxonMobil и ConocoPhillips - не согласились с размером компенсации и отказались проАать свою долю в предприятиях, занимающихся разработкой месторождений в бассейне реки Ориноко. Обе компании вышии из проектов и обратились с иском к правительству Венесуэлы в МежАународный центр по регулированию инвестиционных споров. В 2012 г. арбитражный суА решил, что компенсация 
ExxonMobil домжна составлять 908 млн домларов, а CococoPhillips - 66,8 мин домларов $[14$, с. 396]. Несмотря на суды и конфликты, ConocoPhillips продолжима участвовать в нескольких проектах с государственной PDVSA как на территории Венесуэлы, так и в США. Это свидетельствует о том, что взаимоотношения межАу государствами и ТНК выстраиваются не на какой-то единой жесткой платформе, а имеют гибкую структуру, позволяющую реализовывать несколько, фактически независимых, проектов.

Важно также понимать, что приход крупных инвесторов в страны с авторитарным правительством связан и с его идеологической ориентацией. В том случае, если у власти стоят преАставители «мевого» спектра (коммунисты, социалисты), то экономическая политика может сопровождаться такими действиями, как повышение налогов, ограничения на вывоз капитала, поддержка профсоюзных движений, а в крайнем случае экспроприаџия собственности и запрет деятельности иностранных предприятий. Препятствием такой агрессивной политики может стать экономический спаА или кризис из-за того, что вместе с капиталами и предприятиями уйдут и технологии, например добычи сырья или заводского производства. В этом случае государственные компании будут принимать такие непопулярные меры, как снижение объемов производства, сокрашение персонала, поддержка убыточных предприятий. В конечном счете это приведет к недовольству и протестам уже против «мевого» правительства.

К сожалению, в силу требований по объему, многие феномены и проблемы взаимодействия транснациональных корпораций и государства остались за рамками представленной публикации. Но по первому приближению к Аанной тематике можно сделать несколько выводов и обозначить дальнейшие темы исследований.

Во-первых, инструменты взаимодействия ТНК и современного государства являются предметом изучения џелого ряда соџиальных научных дисциплин. Политическая наука можкет внести свой вклад в это направление благодаря своей ориентации на анализ властных ресурсов и процесс принятия решений политическими субъектами, основным из которых явмяется государство.

Во-вторых, важным объектом изучения должны стать политические стратегии ТНК и правительства принимающей страны, применяемые в зависимости от условий взаимодействия.

В-третьих, важной переменной, определяющей стратегии взаимодействия ТНК и государства, явмяется установившийся политический режим. В Аанной статье пришлось ограничиться анализом тех проблем, с которыми сталкиваются крупные корпорации в странах с авторитарным политическим режимом. Все их многообразие не может ограничиться случаями, приведенными здесь.

В дальнейших исследованиях следует уделить внимание политическим стратегиям ТНК в странах с демократическим режимом, рассмотреть спектр пробцем, с которыми сталкиваются обе стороны при взаимодействии. Интересно также выявить инструменты влияния транснациональных корпораций на внутреннюю и внешнюю политику страны базирования. Ограничивается $\Lambda и$ их влияние только Аоббизмом и GR или в хоА иАут более изощренные среАс- 
тва? Третьим направлением анализа может стать роль ТНК в смене неугодных им политических элит и их действия в странах со слабыми государственными институтами ици в странах, где идут военные и гражданские конфликты.

\section{Библиографический список}

1. Мовсесян А.Г. Транснационализация в мировой экономике: учебное пособие. М., 2001.

2. Портер М. Международная конкуренция. М., 1993.

3. Коуз Р. Фирма, рынок и право. М., 2007.

4. Торкунов А.В. Современные международные отношения и мировая политика: учебник. M., 2004.

5. Кузьмина Т.И. Международный менеджмент. Управление в международных компаниях: учебник. М., 2004.

6. Минцберг Г., Куинн Дж.Б., Гошал С. Стратегический процесс. СПб., 2011.

7. Carasco E.F., Singh J.B. Towards holding transnational corporations responsible for human rights // European Business Review. 2010. № 4. P. 432-445.

8. Aggarval R., Berrill J., Hutson E., Kearney C. What is multinational corporation? Classifying the degree of firm-level multinationality // International Business Rewiew. 2011. № 20. P. 557-577.

9. Доклад о мировых инвестициях 2013. Обзор. Глобальные производственные системы: инвестиции и торговля в интересах развития. Конференция организации объединенных наций по торговле и развитию ЮНКТАД. URL: http://unctad.org/en/PublicationsLibrary/ wir2013overview_ru.pdf

10. Холдоров О.Н. Место и роль нетрадиционных акторов в мировой политике // Вестник Поволжского института управления. 2017. № 1. С. 38-44.

11. Вернон Р. Буря над многонациональными. М., 1982.

12. Boddewyn J.J., Brewer T.L. International-Business political behavior: new theoretical directions // Academy of Management Review. 1994. № 1. P. 119-143.

13. Shell knew. Emails show senior executives at UK's biggest company knew it was party to a vast bribery scheme // Global Witness. 2017.

14. Платошкин Н.Н. Венесуэла и Чавес: биография страны и человека. М., 2015. 